\title{
ANALISA KERJA MANIFOLD ABSOLUTE PRESSURE (MAP) DAN KADAR KANDUNGAN EMISI GAS BUANG YANG DIHASILKAN PADA MOTOR BENSIN DENGAN SISTEM INJEKSI ELEKTRONIK TYPE D-EFI
}

\author{
Oleh : \\ Toto Sugiarto \\ Jurusan Teknik Otomotif, Fakultas Teknik, Universitas Negeri Padang \\ (Telp.+6281261016012, E-mail: totosugiarto5526@yahoo.co.id)
}

\begin{abstract}
This research is aim to : (1) Describe how Manifold Absolute Pressure (MAP) works at low, middle and high level rotation machine; (2) Knowing Levels of Exhaust Emission Content at low, middle and high level rotation machine. Experiment method was used for this research. EFI engine which is using MAP has been analyzed. Scan tool used to observe MAP performance and Four Gas Analyzer to detect and measure Exhaust Emission Content. From experiment found that increasing the spin machine will result in a decrease vacuum of the intake manifold. At low level rotation $(750 \mathrm{rpm})$ the average of air vacuum through the MAP is $29.00 \mathrm{Kpa}$, the middle level (2000 rpm) is $26.67 \mathrm{Kpa}$, and at high speed level (5000 rpm) is 27,33 Kpa.
\end{abstract}

Keywords : Electronic Fuel Injection, Manifold Absolute Pressure, Scan Tool, Four Gas Analyzer, Emission Gas, Electronic Injection System Type D-EFI.

\section{PENDAHULUAN}

Pada motor bensin, sistem pengaturan bahan bakar pada kendaraan bermotor telah mengalami peningkatan secara signifikan. Pengaturan tersebut bertujuan untuk mendapatkan pola penyemprotan bahan bakar agar dapat bercampur dengan udara secara homogen. Campuran yang homogen pada ruang bakar dapat menyebabkan proses pembakaran yang lebih sempurna sehingga menghasilkan emisi gas buang lebih sedikit. Sistem EFI mengunakan konsep pencampuran udara dan bahan bakar terjadi pada saluran masuk (intake manifold) dengan mengunakan sebuah injektor untuk menyemprotkan bahan bakarnya. Pola pengaruran saat penyemprotan bahan bakar ke dalam intake manifold diatur oleh sebuah
Electronic Control Unit (ECU). ECU akan mendapatkan beberapa sensor untuk meyemprotkan bahan bakar dengan saat dan jumlah yang tepat sesuai dengan putaran mesin. Perbandingan jumlah bahan bakar dan udara yang sesuai akan menyebabkan terjadinya pembakaran yang sempurna untuk menghasilkan tenaga yang optimal dan emisi gas buang yang ramah lingkungan. Hampir seluruh kendaraan terbaru telah mengunakan sistem EFI.

Pada sistem EFI terdapat dua jenis sistem yaitu L-EFI dan D-EFI. Perbedaan mendasar pada kedua sistem tersebut adalah pada L-EFI terdapat sebuah sensor pengukur jumlah udara yang masuk kedalam intake manifold (Mass Air Flow Sensor). Sedangkan pada D-EFI terdapat sensor tekanan 
udara pada intake manifold (Manifold Absolute Pressure).

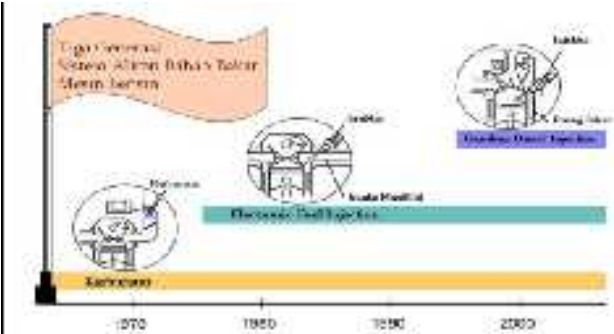

Gambar 1. Tiga generasi sistem bahan bakar

Semua kendaraan berbahan bakar minyak pasti akan menghasilkan gas buang. Gas buang motor bensin jauh lebih berbahaya dibandingkan dengan motor diesel, gas buang motor bensin pada umumnya tidak terlihat oleh mata namun sangat membahayakan untuk kelangsungan hidup manusia. Motor bensin lebih dominan unsur $\mathrm{CO}, \mathrm{HC}$, dan $\mathrm{Pb}$. Motor diesel lebih dominan unsur $\mathrm{SO}_{2}$ dan unsur Carbon yang menimbulkan kepekatan asap knalpot.

Dalam jurnal ini penulis akan mencoba untuk mendeskripsikan kerja sistem EFI yang mengunakan Manifold Absolute Pressure (MAP) pada putaran mesin rendah, menengah dan tinggi. Selain itu penulis juga bermaksud untuk mengetahui tingkat kandungan emisi gas buang yang dihasilkan oleh kendaraan yang mengunakan D-EFI pada putaran rendah, menengah dan tinggi, yang akan digunakan dalam kajian sistem EFI secara lebih mendalam.

\section{METODE PENELITIAN}

Jenis dan Desain Penelitian

Jenis penelitian yang digunakan pada penelitian ini adalah penelitian eksperimen, dimana peneliti menguji langsung pada peralatan yang diteliti untuk mendapatkan data.

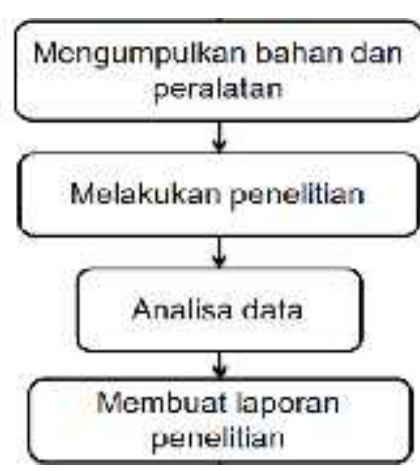

Gambar 2. Desain Penelitian

\section{Alat dan Bahan Penelitian}

Pengambilan data kerja sistem DEFI dilakukan dengan mengunakan scan tools dan pengujian emisi gas buang dilakukan dengan four gas analyzer untuk mendapatkan kandungan emisi gas buang, yaitu: $\mathrm{Co}_{2}, \mathrm{Co}, \mathrm{HC}$, dan $\mathrm{O}_{2}$.

Mesin yang mengunakan sistem D-EFI dan yang akan digunakan dalam penelitian ini adalah mesin Toyota Avanza keluaran tahun 2009.

Teknik Analisa Data

Teknik analisis kerja MAP dilakukan dengan analisis deskriptif pada hasil pengujian dengan memperhatikan kerja yang terjadi pada masing-masing sistem EFI dan putaran mesin.

Data penelitian ini kemudian dianalisis seberapa besar pengaruh dari kerja MAP pada kandungan emisi gas buang kendaraan dengan menggunakan uji beda yaitu $t$ test. Untuk mengetahui tingkat signifikan antara kedua sistem EFI tersebut, maka data tersebut dihitung dengan analisa uji t. Untuk mengetahui taraf signifikan kedua hasil uji tersebut akan di bandingan dengan harga tabel pada taraf signifikan $5 \%$ apabila diperoleh harga $t$ hitung yang melebihi harga $t$ table.

\section{Teknik Penjamin Keabsahan Data}

Keabsahan data yang diperoleh di lapangan diperiksa dengan menggunakan teknik-teknik yang 
disarankan oleh Lincoln and Guba dalam mahir (2007) yaitu keterpercayaan, dapat dipertanggung-jawabkan dan kepastian atau objektif.

\section{HASIL DAN PEMBAHASAN}

Hasil pengujian MAP seperti terlihat pada Tabel 3 .

Tabel 1. Hasil pengujian MAP

\begin{tabular}{|c|c|c|c|c|c|}
\hline No & 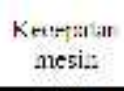 & 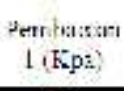 & $\begin{array}{c}\text { Fem bastim } \\
2(\mathrm{~K} f \mathrm{a})\end{array}$ & 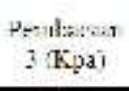 & $\begin{array}{c}\text { Rats-rsta } \\
\text { h:asil } \\
\text { (K) }\end{array}$ \\
\hline 1 & 750 & S11 & 28 & 20 & $2+: 1.1$ \\
\hline 2 & -200 & 26 & 26 & 27 & 26,33 \\
\hline 3 & 2000 & 27 & 27 & 26 & 26,67 \\
\hline 1 & 3000 & 26 & 25 & 25 & 25.33 \\
\hline$\xi$ & 1000 & 28 & 26 & $2 i$ & 26,67 \\
\hline 6 & $\operatorname{scco}$ & 28 & 27 & 27 & 27,33 \\
\hline
\end{tabular}

Dari Tabel 1 dapat diketahui bahwa meningkatnya putaran mesin akan mengakibatkan terjadinya penurunan kevakuman pada saluran intake manifold.

Pada kecepatan rendah (750 rpm) kevakuman udara yang melalui MAP adalah rata-rata adalah $29,00 \mathrm{Kpa}$, pada putaran menengah (2000 rpm) kevakumannya 26,67 Kpa, dan pada putaran tinggi (5000 rpm) kevakuman udara yang melalui MAP sebesar 27,33 Kpa.

Hal ini terjadi karena pada putaran rendah katup throttle masih dalam posisi menutup, sedangkan pada putaran menengah dan tinggi katup throttle sudah mulai terbuka. Hal ini mempengaruhi besarnya kevakuman yang terjadi pada saluran masuk yang tetdeteksi oleh sensor MAP.

Tabel 2. Rata-rata hasil pengujian emisi gas buang

\begin{tabular}{|c|c|c|c|c|}
\hline \multirow{2}{*}{ 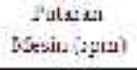 } & \multicolumn{4}{|c|}{ IIa:a-rata | Issil fengujian } \\
\hline & rofos) & HE ipkas: & $r_{0}, 21 \% i$ & on: \\
\hline 796 & 1.47 & 247,00 & 10.25 & 0.54 \\
\hline 1200 & 0,33 & 190,33 & $10 ; 3$ & 0,32 \\
\hline 2000 & $0,2.2$ & $1 \angle \bar{z}, 67$ & $1,7,70$ & $0,4,7$ \\
\hline 3000 & 0,21 & 95,00 & 10,92 & 0,37 \\
\hline 1000 & 0,14 & $4 \pi, 67$ & 11,20 & 0,22 \\
\hline 5000 & 0,02 & 14,$6 ;$ & 11,90 & 0,10 \\
\hline
\end{tabular}

Dari Tabel 2 dapat di ketahui kadar Co akan semakin mengecil seiring dengan meningkatnya putaran mesin.
Pada kendaraan yang mengadopsi UERO 3 kadar Co sebaiknya sangat kecil sekali. Sedangkan kadar HC juga semakin mengecil siring dengan meningkatnya putaran mesin. Pada putaran rendah kadar HC tinggi di mungkinkan proses pembakaran dalam ruang bakar terjadi tidak sempurna.

Kesempurnaan pembakaran akan menghasilkan kadar HC yang semakin kecil. Pembakaran yang baik sebaiknya menghasilkan kadar $\mathrm{CO} 2$ lebih besar. Hal tersebut dikarenakan proses pembakaran dalam ruang bakar yang hasilkan $\mathrm{H} 2 \mathrm{O}$ dan $\mathrm{Co} 2$, kadar ini dibutuhkan oleh tumbuh-tumbuhan untuk berfotosintesis. Sedangkan mesin yang menghasilkan pembakaran lebih baik akan menghasilkan timbul air pada lubang knalpotnya.

Jika dilihat dari kadar $\mathrm{O} 2$ yang dihasilkan oleh emisi gas menandakan adanya kebocoran pada sistem mufler atau sistem pembakaran didalam ruang bakar yang tidak sempurna. Jika pada sistem pembakaran menghasilkan $\mathrm{O} 2$ yang meningkat dan timbul asap dari sistem pembakaran, menandakan adanya ketidak sempurnaan pembakaran di dalam ruang bakar. Sistem mesin harus dilakukan pengecekan untuk menghidari terjadinya kerusakan secara lebih parah.

Dari hasil pengujian kerja MAP, terlihat pada gambar 3, pada putaran idle (750 rpm) kevakuman yang terjadi pada saluran masuk sebesar $29 \mathrm{Kpa}$, dan akan mengalami penurunan menjadi 26,33 Kpa pada saat putaran mesin dinaikan pada putaran $1200 \mathrm{rpm}$.

Kevakuman akan semakin berkurang jika putaran terus dinaikkan menjadi 3000 rpm, kevakuman yang terjadi menjadi 25,33 Kpa. Namun demikian kevakuman akan bertambah jika putaran mesin dinaikan menjadi $4000 \mathrm{rpm}$ dan $5000 \mathrm{rpm}$, seperti terlihat pada gambar di atas. Dengan demikian kerja dari MAP sangat dipengaruhi oleh besarnya kevakuman yang terjadi pada 
saluran masuk, dan perubahan besarnya pembukaan katup trottle.

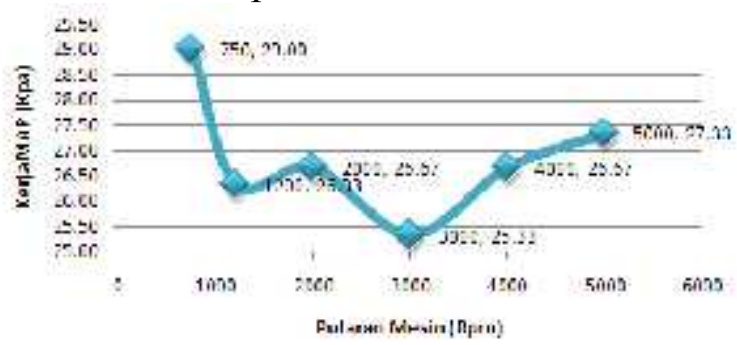

Gambar 3. Grafik Hasil Pengujian Kerja MAP

Besarnya perubahan kevakuman yang terjadi pada saluran masuk ini dideteksi oleh sensor MAP, dimana melalui terminal PIM (pressure intake manipold) dikirim besarnya perubahan tegangan kerja ke ECU, perubahan tegangan kerja pada PIM dijadikan acuan untuk mengatur besarnya jumlah bahan bakar yang akan disemprotkan oleh injektor dan saat pengapian pada busi.

Mengacu pada gambar 4, besarnya $\mathrm{CO}_{2}$ akan semakin meningkat dengan semakin bertambahnya putaran mesin. Hal ini menggambarkan kondisi mesin yang digunakan dalam penelitian ini masih dalam kondisi yang baik.

Pada putaran $700 \mathrm{rpm}$ besarnya kandungan $\mathrm{CO}_{2}$ nya sebesar $10,25 \%$ dan saat putaran tinggi (5000 rpm) besarnya kandungan $\mathrm{CO}_{2}$ nya $11,90 \%$. Besarnya kandungan $\mathrm{CO}_{2}$ pada mesin yang sudah menggunakan sistem injeksi bahan bakar bensin (electronic fuel injection) yaitu 10 $-16 \%$.

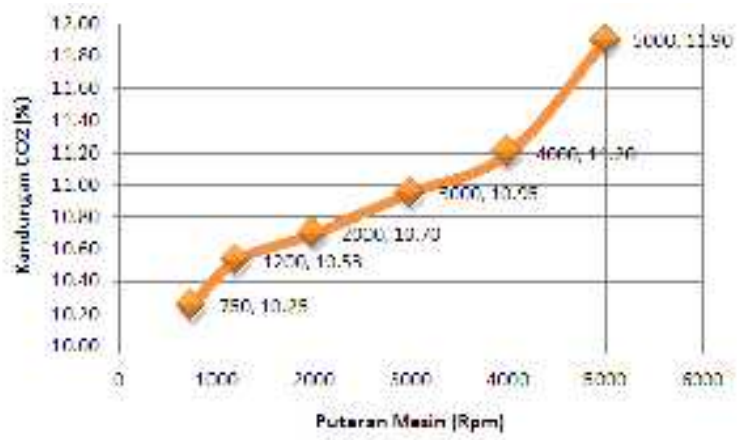

Gambar 4. Grafik Pengujian Kandungan Emisi $\mathrm{CO}_{2}$ Engine EFI dengan MAP

Besarnya kandungan $\mathrm{CO}_{2}$ yang diukur dengan menggunakan four gas analyzer, menjadi indikator sebuah mesin masih baik atau tidak. Semakin tinggi kadar nilai $\mathrm{CO}_{2}$ menunjukan efesiensi pembakaran yang terjadi di dalam silinder. Jika sebuah motor bensin kandungan $\mathrm{CO}_{2}$ nya dibawah $10 \%$, menunjukkan mesin tersebut sudah tidak baik kondisinya.

Apabila kandungan $\mathrm{CO}_{2}$ nya tinggi, maka kandungan emisi $\mathrm{CO}, \mathrm{HC}$ dan $\mathrm{O}_{2}$ nya akan rendah, tetapi sebaliknya. Jika kandungan $\mathrm{CO}_{2}$ nya rendah (dibawah 10\%), makan kandungan emisi $\mathrm{CO}, \mathrm{HC}$, dan $\mathrm{O}_{2}$ nya akan menjadi tinggi. Indikator dalam pengujian emisi gas buang motor bensin adalah dengan melihat kandungan $\mathrm{CO}_{2}$ nya terlebih dahulu, selanjutnya kita melihat kandungan emisi yang lainnya.

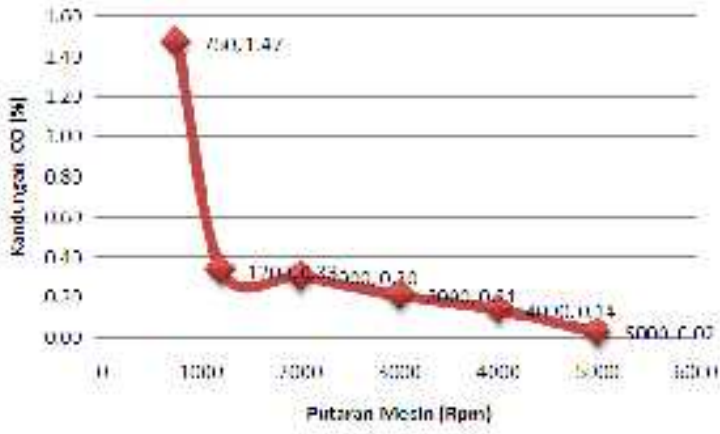

Gambar 5. Pengujian Kandungan Emisi $\mathrm{CO}$

Berdasarkan hasil pengujian kandungan $\mathrm{CO}$ grafik di atas, dapat terlihat kandung $\mathrm{CO}$ akan semakin menurun dengan bertambahnya putaran mesin. Standar besarnya nilai CO untuk mesin yang sudah menggunakan sistem injeksi bahan bakar bensin (EFI) adalah $0-2 \%$. Hal ini berarti kondisi engine yang digunakan dalam penelitian ini masih dalam kondisi yang baik. Hal ini karena kandungan nilai $\mathrm{CO}$ nya masih dibawah dari nilai yang ditentukan. 


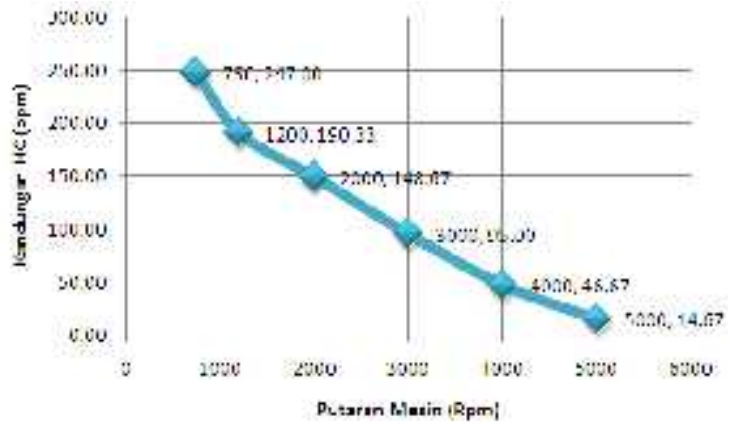

Gambar 6. Pengujian Kandungan Emisi $\mathrm{HC}$

Mengacu pada gambar 5 dapat dijelaskan bahwa besarnya kandungan $\mathrm{HC}$ akan semakin menurun dengan bertambahnya putaran mesin.

Pada putaran idle $(700 \mathrm{rpm})$ besarnya kandungan HC 247 ppm, sedangkan pada putaran tinggi (5000 rpm) besarnya kandungan $\mathrm{HC} \quad 14,67$ ppm.

Besarnya standar kandungan Hidro Carbon pada mesin dengan sistem injeksi bahan bakar bensin adalah 0 200 ppm (maksimal 200 ppm). Dari data diatas dapat terlihat pada putaran idle kandungan $\mathrm{HC}$ lebih besar dari nilai standar, hal ini menunjukan kualitas pembakaran belum sempurna. Besarnya nilai kandungan $\mathrm{HC}$ dopengaruhi oleh kualitas sistem pengapian, jika kandungan $\mathrm{HC}$ nya tinggi, maka sistem pengapian pada kendaraan tersebut mengalami kerusakan.

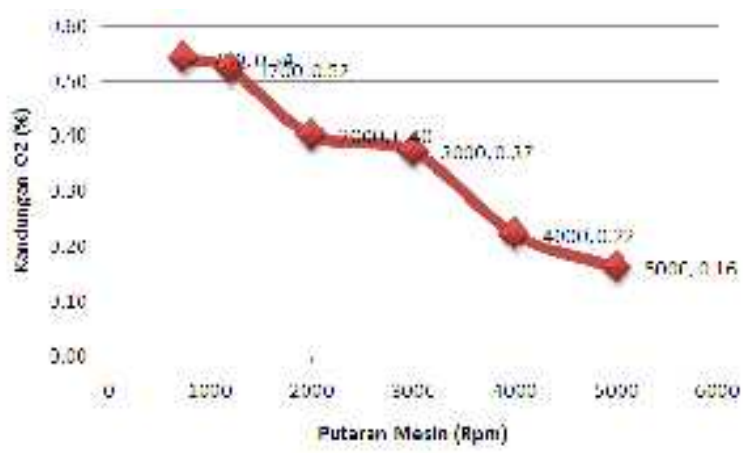

Gambar 7. Pengujian Kandungan Emisi $\mathrm{O}_{2}$

Berdasarkan tabel pengujian kandungan $\mathrm{O}_{2}$ diatas, pada putaran idle (750 rpm) Kandungan $\mathrm{O}_{2}$ nya adalah
$0,54 \%$ dan pada putaran tinggi (5000 rpm) $\mathrm{O}_{2}$ nya adalah $0,16 \%$. Standar besarnya nilai $\mathrm{O}_{2}$ untuk motor bensin yang sudah dengan sistem injeksi bahan bakar adalah $0-2 \%$. Hal terjadi dalam silinder sempurna. Jika kandungan $\mathrm{O}_{2}$ nya di atas $2 \%$ berarti terjadinya campuran kurus pada proses pembakaran motor, dimana jumlah udara yang dibakar lebih banyak dari jumlah bensin yang disemprotkan oleh injektor.

\section{KESIMPULAN}

Manifold Absolute Pressure (MAP) digunakan pada EFI tipe D untuk menyensor tekanan udara yang masuk kedalam ruang bakar, MAP adalah salah satu sensor penting pada EFI tipe D.

Pada beberapa pengujian yang telah dilakukan di atas, dapat diketahui bahwa meningkatnya putaran mesin akan mengakibatkan terjadinya penurunan kevakuman pada saluran intake manifold. Pada kecepatan rendah (750 rpm) kevakuman udara yang melalui MAP adalah rata-rata adalah 29,00 Kpa, pada putaran menengah (2000 rpm) kevakumannya 26,67 Kpa, dan pada putaran tinggi (5000 rpm) kevakuman udara yang melalui MAP sebesar 27,33 Kpa.

Dari pengujian emisi gas buang di atas dapat di ketahui kadar $\mathrm{CO}$ akan semakin mengecil seiring dengan meningkatnya putaran mesin. Sedangkan kadar HC juga semakin mengecil siring dengan meningkatnya putaran mesin. Pada putaran rendah kadar HC tinggi di mungkinkan proses pembakaran dalam ruang bakar terjadi tidak sempurna. Kesempurnaan pembakaran akan menghasilkan kadar HC yang semakin kecil. Pembakaran yang baik sebaiknya menghasilkan kadar $\mathrm{CO}_{2}$ lebih besar. Hal tersebut dikarenakan proses pembakaran dalam ruang bakar yang hasilkan $\mathrm{H}_{2} \mathrm{O}$ dan $\mathrm{Co}_{2}$, kadar ini dibutuhkan oleh tumbuh-tumbuhan untuk berfotosintesis. Sedangkan mesin 
yang menghasilkan pembakaran lebih baik akan menghasilkan timbul air pada lubang knalpotnya.

\section{SARAN}

Penelitian ini disarankan agar dapat dilanjutkan dengan pengambilan data yang lebih beragam dengan menggunakan lebih banyak mesin yang dijadikan sampel penelitian, sehingga dapat memberikan masukan yang lebih baik.

Penelitian ini dapat dilanjutkan dengan meneliti sensor-sensor lainnya pada motor bensin yang menggunakan sistem bahan bakar injeksi bensin elektronik (electronic fuel injection/EFI), dan D-EFI lainnya.

\section{DAFTAR PUSTAKA}

Daihatsu. (2010). Engine Step 1 Training. Jakarta. PT Daihatsu Astra Motor

Gunadi. (2010). Pengaruh Waktu Pengapian (Ignition Timming) Terhadap Emisi Gas Buang Pada Mobil Dengan Sistem Bahan Bakar EFI. Yogyakarta. Hasil Penelitian Di Universitas Negeri Yogyakarta.

Iman Mahir. (2007). Metode Penelitian. Padang: Makalah Di Sajikan Pada Pelatihan Penelitian Di Pusat Pengembangan Ilmiah dan Penelitian Mahasiswa Universitas Negeri Padang (PPIPM UNP) 4 Januari 2007.

Junisra Syam. (2009). Sistem bahan bakar EFI. Jakarta. PT. TTA International

Leo priyandoko. (2009). Sistem EFI. Jakarta. Di Sajikan Pada Pelatihan Sistem EFI di Jakarta.

TTA. (2010). Dasar-Dasar Sistem EFI. Jakarta: PT. TTA International
Toyota. (2010). Training Engine Step I. Jakarta. PT. Toyota Astra Motor 